\title{
Ethological description of a fixed action pattern in a kissing bug (Triatominae): vision, gustation, proboscis extension and drinking of water and guava
}

\author{
Oscar Páez-Rondón ${ }^{1,4} \cdot$ Elis Aldana ${ }^{2} \cdot J^{\prime}$ Joseph Dickens ${ }^{3} \cdot$ Fernando Otálora-Luna ${ }^{4}$
}

Received: 22 May 2017 / Accepted: 20 March 2018 / Published online: 13 April 2018

○ Japan Ethological Society and Springer Japan KK, part of Springer Nature 2018

\begin{abstract}
Triatomines (Heteroptera, Reduviidae) are vectors of Trypanosoma cruzi, the etiological agent of Chagas disease in America. These true bugs have traditionally been considered to be blood suckers, although some species have been catalogued as being entomophagous. By using their highly specialized mouthparts, these insects have evolved a stereotyped habit which includes lifting up the proboscis, piercing and sucking, when the occasion arises. Most triatomines bite their sleeping and unaware vertebrate or invertebrate hosts, but they can also search for other targets, guided, in part, by visual and chemical stimuli. In this study, we observed that triatomines apparently visually identify a drop of water in the distance, then taste it with their legs, upon which proboscis extension and sucking ensues. This invariant behavior or fixed action pattern, observed in several triatomine species (Rhodnius prolixus, Triatoma infestans and Panstrongylus geniculatus), was also elicited by a dummy drop of water and guava fruit. We discuss evolutionary and ethological aspects of this innate behavior. Digital video images related to this article are available at http://www.momo-p.com/showdetail-e.php?movieid=momo180314rp01a and http://www.momo-p.com/showdetail-e.php?movieid=momo180314rp03a.
\end{abstract}

Keywords Proboscis-extension reflex $\cdot$ Innate releasing mechanism $\cdot$ Rostrum $\cdot$ Behavioral sequence $\cdot$ Intuition $\cdot$ Kleptophagy

"All this I swallow, it tastes good, I like it well, it becomes mine..."

Walt Whitman

Fernando Otálora-Luna

otaloraluna@gmail.com; otalora@ula.ve

1 Unidad de Articulación Comunitaria, Centro Multidisciplinario de Ciencias, Instituto Venezolano de Investigaciones Científicas, Loma de Los Guamos, Jají, Mérida 5107, Bolivarian Republic of Venezuela

2 Laboratorio de Entomología "Herman Lent," Departamento de Biología, Facultad de Ciencias, Universidad de Los Andes, Mérida 5101, Bolivarian Republic of Venezuela

3 Department of Biology, University of Richmond, Richmond, VA 23173, USA

4 Laboratorio de Ecología Sensorial, Centro Multidisciplinario de Ciencias, Instituto Venezolano de Investigaciones Científicas, Loma de Los Guamos, Jají, Mérida 5107, Bolivarian Republic of Venezuela

\section{Introduction}

A fixed action pattern (FAP) denotes a highly stereotyped behavioral sequence released by a particular stimulus (Kogon 1941; Lorenz 1981). This instinctive behavior is relatively invariant within a species, and once initiated almost inevitably runs to completion. FAPs are produced by a "hard-wired" neural network known as an innate releasing mechanism, which releases a conventional behavior in response to sensory input. Although it is very tempting to assign an adaptive value to a FAP, some authors have proposed that such innate phenotypic patterns exist as inevitable expressions of universal principles beyond natural selection, i.e., exaptations (sensu amplo Gould and Vrba 1982) or structural adaptations (sensu stricto Croizat 1962; Grehan 1984).

Triatomines (Hemiptera: Reduviidae) are referred to as "kissing bugs" because they usually bite close to the mouth of humans, and have evolved mouthparts highly specialized for piercing and blood sucking, which they lift and extend when the occasion arises. Such proboscis extension has the 
appearance of a FAP. Given its complexity and its leading role in energy and water supply, proboscis-extension behavior was not left to the variability of learning during the course of triatomine hematophagous evolution (OtáloraLuna et al. 2015b). On the contrary, this behavior became innate in order to be structurally robust. Triatomine proboscis extension serves to provide a blood meal to the insect, a drink from a source of water, or even another function with a debatable adaptive value, i.e., the pleasure function (Tiffin 2016; Mendl et al. 2011; Paul and Mendl 2016). If triatomine proboscis lifting is part of a FAP, what kind of stimuli elicit it and what is its evolutionary value? Can a drop of clean water or a fruit like guava, or even a simple piece of plastic, elicit proboscis lifting and liquid sucking?

Triatomines are vectors of the etiological agent of Chagas disease Trypanosoma cruzi in America. Several triatomine species live in or visit human dwellings (Otálora-Luna et al. 2015a). These bugs are nest-living insects, and given that they share very intimately their nest with their host, are considered a type of ectoparasite (e.g., ticks and lice). Although most triatomines require vertebrate blood to survive, Sandoval et al. (2015) have demonstrated by morphometric analysis that Belminus species are entomophagous; contrary to other triatomine species that have been observed practicing hemolymphagy on cockroaches but have not been demonstrated to be able to use such tactics as a prolonged survival strategy (Durán et al. 2016). Furthermore, Díaz-Albiter et al. (2016) found that Rhodnius prolixus is able to derive physiological benefit from water and sugars from tomatoes (Solanum lycopersicum). R. prolixus and Triatoma infestans have been observed practicing cleptohematophagy (i.e., stealing blood from a recently fed congener), also named "hygrokleptism" (Áñez 1982) or "hemolymphagy" (Alves et al. 2011). These bugs have also been observed practicing coprophagy (i.e., feeding on congener feces) (Schaub et al. 1989). While the survival value of many such sucking behaviors is unknown, their occurrence casts doubts about bloodsucking as a diagnostic taxonomic feature, and as a phylogenetic character, for the Triatominae subfamily. However, there is no doubt that the principal sources of food are hemolymph for Belminus species (Sandoval et al. 2013), and blood for the rest of triatomine species.

When a kissing bug approaches a source of blood, it lifts its proboscis from the gula on its head and pierces the host in order to locate blood vessels. Heat alone, transmitted by radiation or convection, is sufficient to elicit proboscis extension (Wigglesworth and Gillett 1934a, b; Schmitz et al. 2000; Ferreira et al. 2007; Fresquet and Lazzari 2011). However, are vision or gustation, or any other stimulus, alone able to elicit such proboscis lifting? Which visual or chemical stimuli are relevant for such behavior?

While there are several studies concerning the role of vision in triatomine behavior (Ward and Finlayson 1982;
Reisenman and Lazzari 2006; Castro et al. 2010), this sense has not received as much attention as olfaction (OtáloraLuna et al. 2004; Aldana et al. 2005; Otálora-Luna and Guerin 2014; Guerenstein and Lazzari 2009). However, vision has recently gained more interest as it has become apparent that urban lights are important cues attracting triatomines to human dwellings (Pacheco-Tucuch et al. 2012). This research on vision has focused more on emitted light stimuli, rather than on the shape of the visual stimulus.

Given its immense importance in the everyday life of triatomines, it is perhaps surprising that of all their senses the least is known about taste or gustation. For vertebrates, the sense of taste occurs mainly through sensory receptors located in the mouth. Although insects can taste with taste receptors on their mouthparts, they also have taste receptors on their antennae, palps, legs, genitalia and wings (Singh 1997; Raad et al. 2016), and possibly other parts of the body. Most studies of the sense of taste in triatomines have focused on the role of the antennae and piercing mouthparts (Friend and Smith 1977), but taste receptors on the legs (Pontes et al. 2014) may also play an important role in feeding behavior. Given that they walk over their meal, triatomines may use their legs to taste a potential host.

Studies of animal orientation are somewhere between behaviorism (i.e., learning psychology) and ethology (Roeder 1998). Considering Crist (1998) criticism of the semantic style of the founders of ethology, and some stylistic elements used by the pioneers of the behavioral observation of animals (Darwin and Wallace 1858; Darwin 1983; Humboldt 1991), here we perform a descriptive ethogram of a FAP in $R$. prolixus, $T$. infestans and Panstrongylus geniculatus that begins with visual, mechanical and/or gustatory behavior and ends in proboscis lifting and sucking. We discuss evolutionary aspects of this innate behavior.

\section{Materials and methods}

\section{Insects}

Adults of $R$. prolixus, T. infestans and P. geniculatus, and fifth-instar nymphs of $R$. prolixus were fed once a month on live hens and cockerels, and maintained at $23 \pm 2{ }^{\circ} \mathrm{C}$, $82 \pm 7 \%$ relative humidity under a photoregime of 12 -h light and 12-h darkness. Specimens of $P$. geniculatus were collected between 2012 and 2015 from houses in Chiguará, Mérida, Venezuela. $R$. prolixus and T. infestans have been kept in our lab under the previous conditions since 2010. The first $R$. prolixus bugs came from a more than 40 -yearold colony maintained at the "Herman Lent" Laboratory in the Universidad de Los Andes, Mérida, Venezuela. This colony originated in 1972 from the old Malariology Station (Estación de Malariología), now the Dr. Arnoldo Gabaldón 
Institute of Higher Studies of Public Health (Instituto de Altos Estudios de Salud Pública "Dr. Arnoldo Gabaldón”) in Maracay, Venezuela. T. infestans were originally brought by Herman Lent from Argentina. Bugs used in this study were starved for between 4 and 5 weeks. Each bug was used only once to avoid bias from learning. At least five 5th-stage nymphs or five females and five males were used for each experiment.

\section{Arena}

A glass chamber (length $12 \mathrm{~cm}$, width $6 \mathrm{~cm}$, height $2 \mathrm{~cm}$ ) served as an arena for filming (CMOS, EOS Rebel T3, macro lens $100 \mathrm{~mm}$; Canon) the behavior of $R$. prolixus, $T$. infestans and $P$. geniculatus adults and $R$. prolixus fifthinstar nymphs (Fig. 1). Each insect was introduced through a circular door $(1 \mathrm{~cm})$ into the center of the arena roof. This door remained closed during the experiments.

\section{Behavioral bioassays}

The behavior of each individual insect was observed and recorded in the arena for $15 \mathrm{~min}$. The recorded videos were analyzed at a playback speed from $\times 1$ to $\times 0.125$. In addition, anecdotes (sensu Bekoff 2007) of each insect were written in a notebook to build an exhaustive ethogram.

\section{Drop of water}

One drop (35 $\mu \mathrm{l}$, diameter $0.5 \mathrm{~cm}$ ) of distilled water (15 M 2 ) was deposited on the arena floor, which was textured (corrugated) with isotropic roughness geometry to avoid the spreading of the drop, which instead assumed an almost spherical shape (Kusumaatmaja et al. 2008; Semprebon et al. 2009). The water drop was placed in the center of the longest arena axis, and $1 \mathrm{~cm}$ from the extremity of the shortest axis, in order to increase the probability that the bug would encounter the drop given its thigmotactic behavior of walking along the walls of the arena. For our initial experiment, intact $R$. prolixus, $T$. infestans and $P$. geniculatus adults, and $R$. prolixus fifth-instar nymphs were used. For a second series of experiments, the antennae of $R$. prolixus adults and fifth-instar nymphs were cut between the scape and the pedicel with entomological scissors (model 4715; Bioquip) to deprive these individuals of antennal inputs.

\section{Dummy drop}

A spherical dummy (sensu Tinbergen 1986) made of translucent plastic was cut in half (diameter $1 \mathrm{~cm}$ ), to resemble a drop of water. The dummy drop was cleaned with distilled water and placed with forceps on the arena floor at the same position as the drop of water. For these experiments, intact $R$. prolixus adults and fifth-instar nymphs were used.

\section{Guava fruit}

A piece of chopped guava ( $5 \mathrm{~g}$ ) was placed on the arena floor, in the same position as the drop of water, and following the previous protocol of observation. For these experiments, intact $R$. prolixus and $P$. geniculatus adults, and fifthinstar nymphs of $R$. prolixus were used.

\section{Leg manipulation}

Adults of $R$. prolixus were individually restrained in plastic tubing ( $5 \mathrm{~mm}$ diameter $\times 2 \mathrm{~cm}$ length), where the head and first pair of legs of each bug stretched out beyond the edge of the tubing. After leaving the insect for $1 \mathrm{~min}$ to rest in that position, the region between the tarsus and the anterior extreme of tibia, including the fossula spongiosa, was touched with a droplet of distilled water $(5 \mu \mathrm{l})$ applied with a micropipette (Finnpipette, 1-10 $\mu$; Thermo Scientific). The control consisted of touching the distal leg with the tip of the micropipette without water.

\section{Results}

\section{A drop of water elicits a FAP}

Each $R$. prolixus, $T$. infestans and $P$. geniculatus adult, and $R$. prolixus fifth-instar nymph encountered the drop of water when they walked in the experimental arena by vision and/
Fig. 1 Experimental arena where the orientation behavior of Rhodnius prolixus was observed

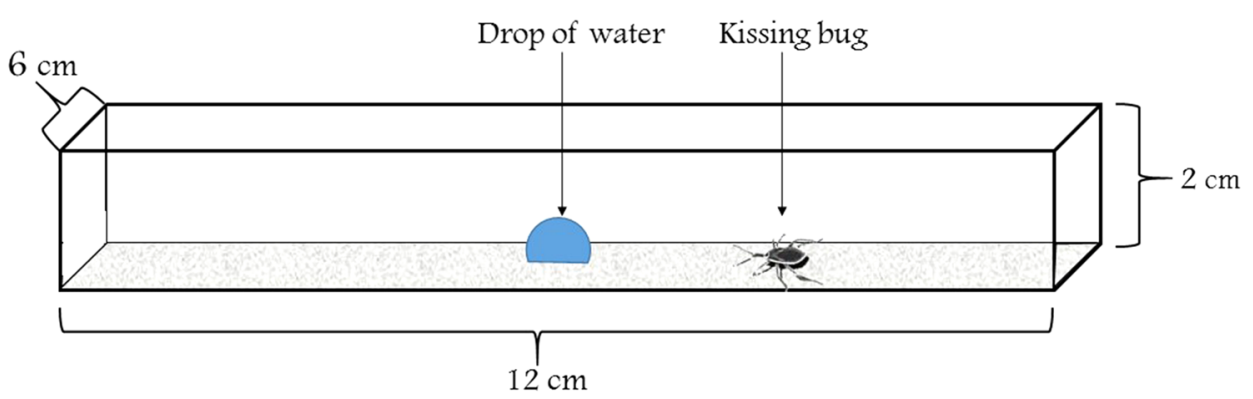


or touch. Adults and fifth-instar nymphs showed similar behaviors, although nymphs, compared to adults, were more reluctant to approach the drop of water.

We observed the following behaviors that suggested that the bugs were able to see the drop of water:

1. Some bugs abruptly dodged the drop of water during walking without touching it.

2. Other bugs walked directly to the drop of water.

3. Others walked cautiously to the drop of water.

In the last two cases, the bugs showed an obvious interest in walking to the drop, as if they were able to see it. Although, these two cases present some ambiguity because our impression of "directly" and "cautiously" are subjective, the former (1) suggests that the bug was able to visually perceive the drop of water as it evaded the obstacle without touching it.

After a while, even the triatomines that initially evaded the drop of water showed interest in this object, and touched it in an explorative attitude with their forelegs and rarely with their middle legs (Fig. 2; counter no. 00:01-05:32 in the video image: http://www.momo-p.com/showdetail -e.php?movieid=momo180314rp01a). The nymphs of $R$. prolixus commonly first touched the drop of water very carefully and then made a step back, moved forward to touch again with the same leg, and immediately extended the proboscis. On the other hand, adults always touched twice with the same leg and immediately drank from the drop of water.

As bugs approached the drop of water, their antennae either did not touch it or touched it only superficially (i.e., antennal exploration), thus preventing entrapment of the antennae by the high surface tension of the water. Movement of the antennae and legs occurred rapidly and repeatedly over the surface of the drop, apparently surveying the area where the drop was placed. Touching with the leg was performed very rapidly and softly, as if "fishing" on the surface, which probably also prevented the limbs from becoming trapped.

In a period that lasted from a fraction of a second to a few seconds, the bug explored the drop of water with its antennae and legs. Subsequently, the bug extended its proboscis, generally to the drop of water, and then retracted it. On some occasions the bug extended its proboscis for a shorter time and then retracted it, but it did not pierce the drop of water. If the bug touched the water with its proboscis, it sucked water for some seconds or even minutes. Finally, it retracted the proboscis and moved on. This drinking behavior lasted 2-5 min in all species studied, but never until gut repletion.

Summarizing, the FAP consisted of: (1) apparent visualization of the drop, (2) approaching, (3) exploring and touching with the antennae and the legs, (4) extension of the proboscis, (5) sucking of the liquid. Finally, at this last moment, the insect decides whether to continue sucking or retract its proboscis and move on (see ethogram in Fig. 3).

\section{Behavior after amputation of the antennae}

As the antennae were apparently involved in sensing the drop of water, probably through hygroreceptors that did not require touching, we cut the antennae of $R$. prolixus adults and observed that leg gustation alone was sufficient to elicit proboscis extension (Fig. 2; counter no. 00:01-00:54 in the video image: http://www.momo-p.com/showdetail -e.php?movieid=momo180314rp01a). Scanning with the scapes (proximal remaining segment of the antennae) was observed before proboscis extension.

\section{Guava fruit and a dummy drop elicit the FAP}

$R$. prolixus and $P$. geniculatus adults and fifth-instar nymphs of $R$. prolixus explored the guava with their antennae and
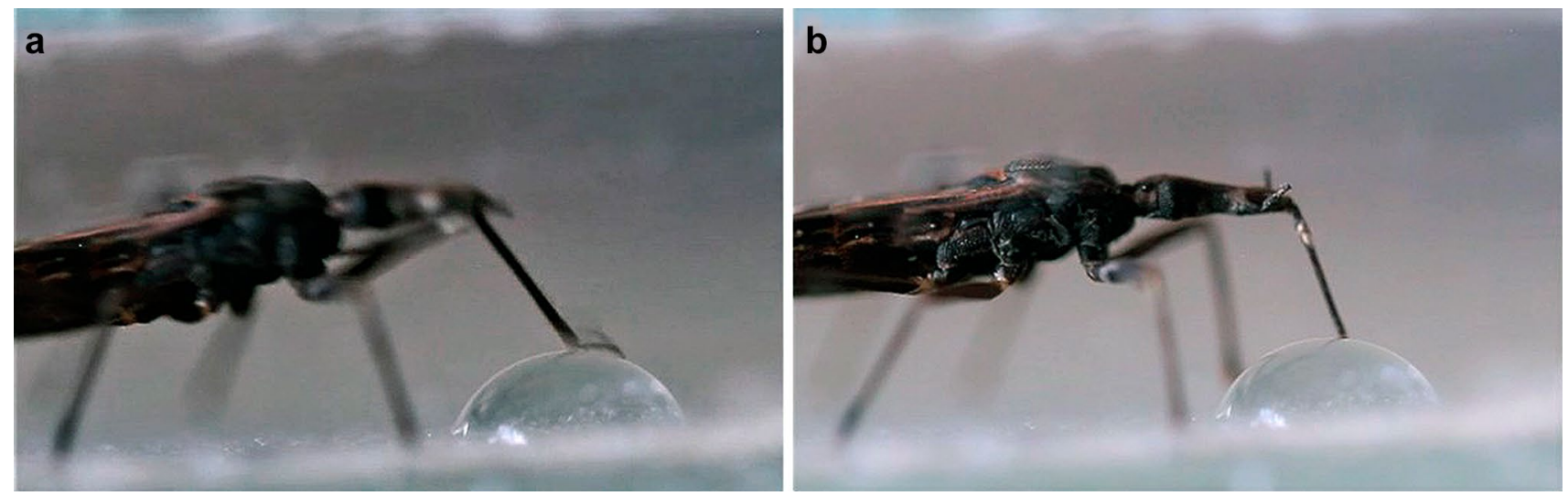

Fig. 2 Video of fixed action pattern (FAP) in Rhodnius prolixus and Panstrongylus geniculatus. Approach to a drop of water with and without antennae extended (http://www.momo-p.com/showdetail-e.php?movieid=momo180314rp01a) 
Fig. 3 Ethogram of FAP: vision, gustation and proboscis extension in a kissing bug. Rectangle Process, parallelogram input, diamond decision, oval start or end, Rp Rhodnius prolixus, Ti Triatoma infestans, Pg Panstrongylus geniculatus. Dashed lines indicate lack of experimental determination. Numbers within parentheses correspond to the fraction of insects that showed such behavior

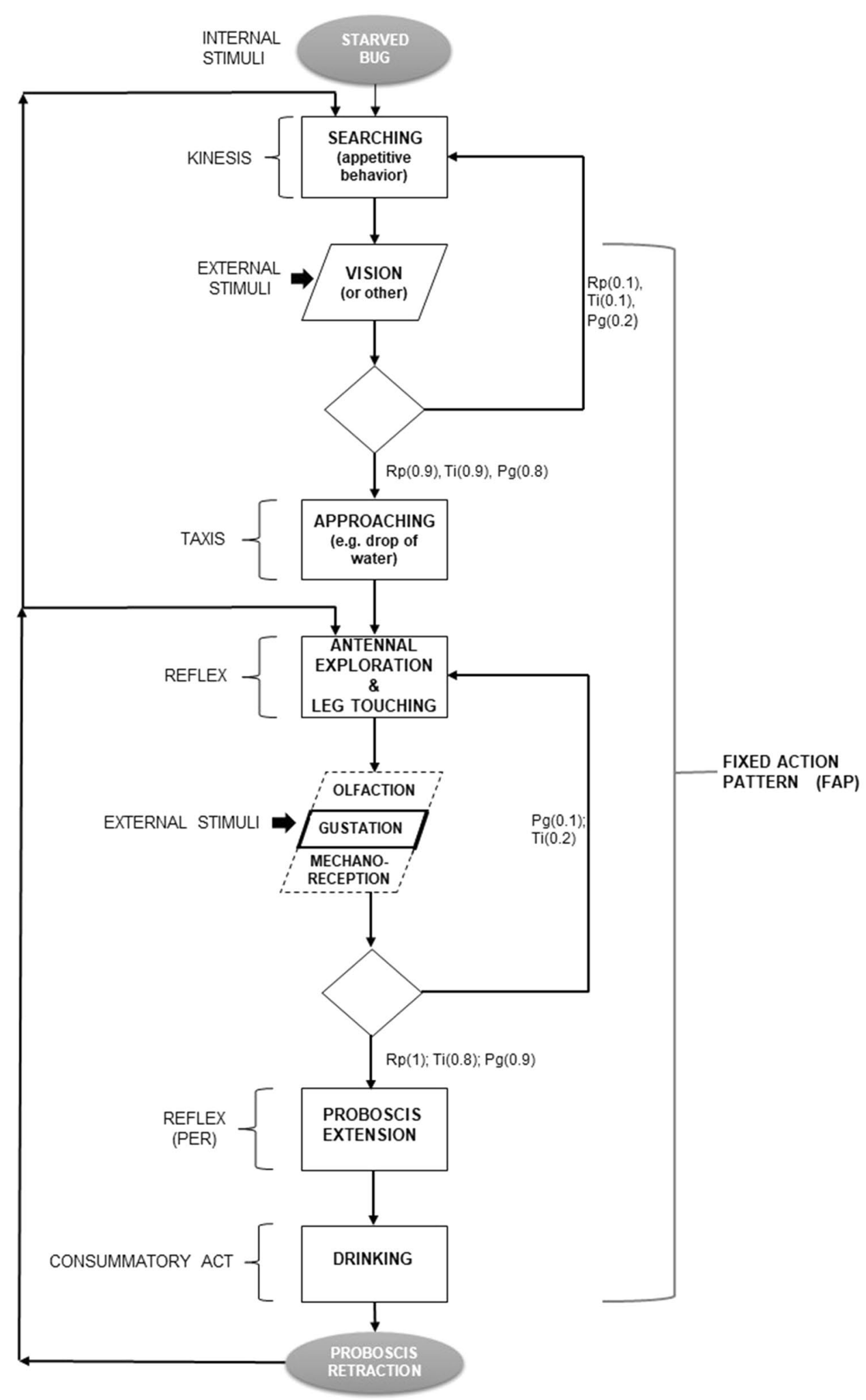

touched it twice with their forelegs, which elicited proboscis extension and feeding behavior for several seconds, showing the same stereotyped behaviors observed vis-à-vis the drop of water.
The spherical dummy made of translucent plastic elicited proboscis extension by $R$. prolixus fifth-instar nymphs, showing the same stereotyped behaviors observed vis-àvis the drop of water (Fig. 4; counter no. 00:01-01:45 in 

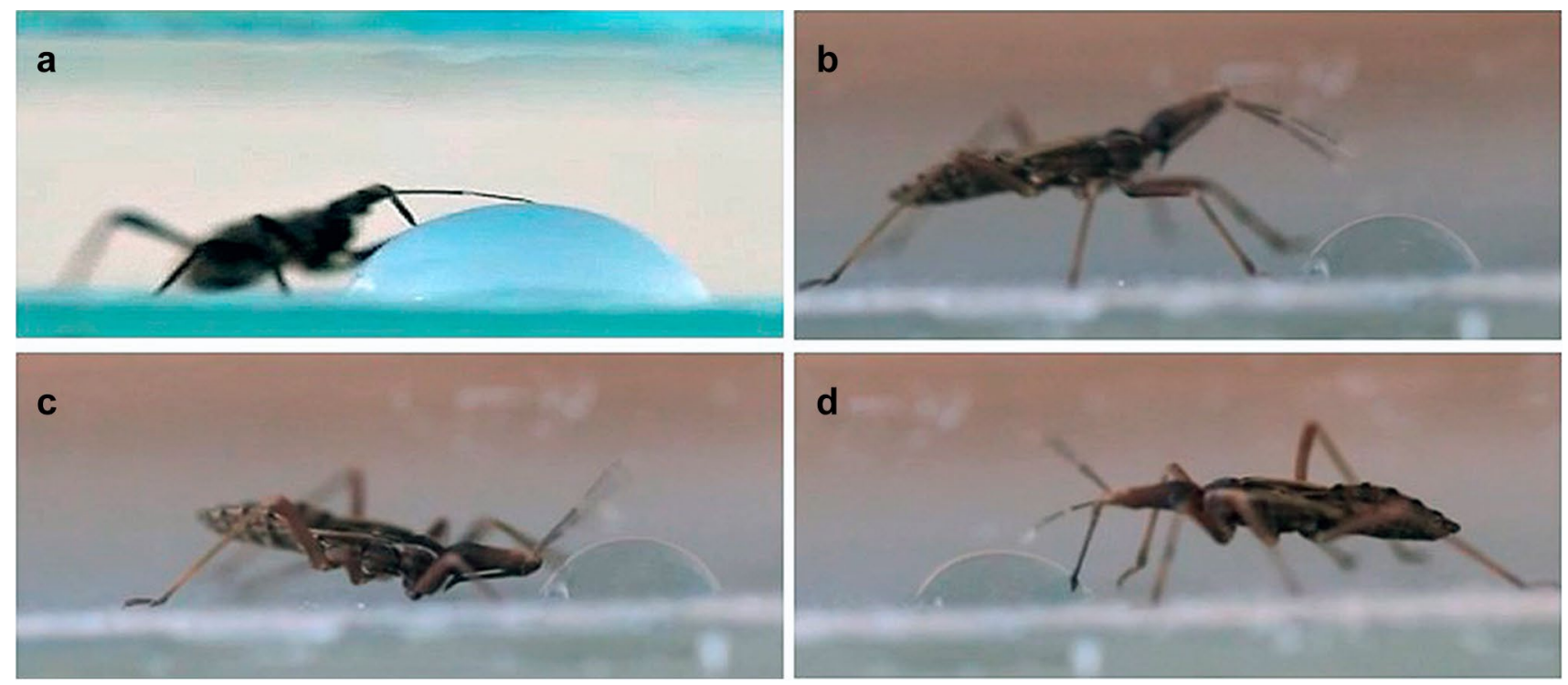

Fig. 4 Video of FAP in R. prolixus vis-à-vis a spherical dummy made of translucent plastic $(\mathbf{a}, \mathbf{b})$ and anecdotal observation where a bug's proboscis was glued to its gula $(\mathbf{c}, \mathbf{d})$. Note that in both cases bugs

the video image: http://www.momo-p.com/showdetail -e.php?movieid=momo180314rp03a).

\section{Proboscis extension elicited by leg touching}

After touching the leg of eight fixed $R$. prolixus adults with a droplet of water, they extended their proboscis for approximately $3 \mathrm{~s}$. After touching the leg of another eight adults with a dry tip of a micropipette, no proboscis extension was observed.

\section{Anecdotal observations}

The proboscis of a $R$. prolixus adult was accidentally glued (with triatomine feces) to the gula (Fig. 4; counter no. 01:5102:42 in the video image: http://www.momo-p.com/showd etail-e.php?movieid=momo180314rp03a), thus preventing proboscis extension. After tasting the drop of water, this bug performed forward and backward "epileptic" (i.e., convulsive lato sensu) movements directed to the drop of water, showing frustration. After several seconds, the insect freed its proboscis, immediately stopped the epileptic movements, and initiated sucking of water.

\section{Discussion}

Triatomines used in this study were starved for 4-5 weeks and showed an appetitive behavior (Immelmann 1983; Otálora-Luna et al. 2004) comprising a period of searching showed edginess in their movements. (http://www.momo-p.com/ showdetail-e.php?movieid=momo180314rp03a)

until locating a stimulant adequate to trigger the consummatory act (Craig 1918; Tinbergen 2006) of drinking. So we presume that the bugs' act of drawing spatially closer to their end, i.e., approaching, was performed under a motivational state. Bugs were so starved that they tried to suck almost everything they encounter. In the context of this motivational state, following Immelmann (1983), here we distinguish appetitive behaviors, which show great variability from consummatory actions, characterized by their stereotype. Immelmann (1983) underline that "In comparing the two sets of concepts we can say that consummatory actions are apparently always fixed action patterns (but not all fixed action patterns are consummatory actions), while appetitive behavior can contain taxis components as well as fixed action patterns." It is interesting to note that the FAP described here as predicted by ethological theory is not affected by external stimuli, e.g., drop of water, guava, dummy, among others, besides their releasing function. Regardless of the diverse appetitive behaviors, after the consummatory act our FAP always retained its form, and as a result of this "form constancy" or "form stereotypy" we propose that the FAP is a typical phenotype for Triatominae and can be used to identify them because its morphological characteristics are preprogrammed as a whole in their structural form and in their genome.

What do we mean by "approach?" Do triatomines perform a directional approach or random approach? As Crist (1998) underlines that the "categories of voluntary and involuntary are much more like poles on a continuum, than mutually exclusive and exhaustive types" we propose 
that most of the behaviors observed here were somewhere between an intentional approach (by necessity) and a stochastic approach (by chance) (García Bacca 1985).

The manner in which the triatomines approached the drop of water, performing rapid stereotyped movements of the legs and antennae, ending this sequence in proboscis lifting and sucking, was invariable. The constancy of the patterns of behavior from initial sensing leading to sucking, the presence of this behavior in the phytophagous bug Lygus lineolaris (Hemiptera: Miridae) — a distant relative of triatomines (Hatfield et al. 1983) - the presence of this behavior in three different triatomine species, and its existence in both nymphs and adults, provides evidence that this phenotype is an "inherited movement coordination" (Erbkoordination, in German) or FAP (Eibl-Eibesfeldt 1979). The FAP described here for kissing bugs, started with searching and an approach to the object to be touched, presumably elicited by vision, but in other cases the encounter may have occurred accidentally. Subsequently the following sequences proceeded: visualization of the target (e.g., drop of water), exploring with the antennae, touching with the legs, extension of the proboscis, and sucking of liquid. At this last stage, as the insect did not find the phagostimulants that are present in blood (Friend and Smith 1977; Guerenstein and Núñez 1994), it stopped gorging and retracted its proboscis, before abdomen swelling. It is also possible that triatomines learned via legs, antennae and other sensory modalities that the liquid was not blood, but they decided to suck small amounts to attend to their starvation and hydration needs. Ethological theory (Eibl-Eibesfeldt 1979) does not disallow that FAPs could be modeled by the learning process and contribute to it. This sequence did not always proceed linearly (Eibl-Eibesfeldt 1979), which suggests it is a prima facie case that this FAP phenomenon occurs in non-linear time (Bailly et al. 2012).

After amputation of the antennae, physical touching by the antenna (i.e., antennal direct contact) was not required for proboscis extension, but before proboscis extension bugs always performed the scape movement (Fig. 2; counter no. 00:01-01:05 in the video image: http://www.momo-p.com/ showdetail-e.php?movieid=momo180314rp01a) associated with antennal exploration. Thus, although antennae touching is not a sine qua non condition required for proboscis extension, antennal movements might be considered as part of the FAP sequence.

The fact that fifth-instar nymphs showed less appetite (more reluctance) toward the object compared to adults, may be associated with maturation of the FAP during the life cycle of triatomines, which goes from taxis to FAP. Usually, the FAP is accompanied by a simple reflex and coordinated taxis (Lorenz 1977). Reflexes are simpler behaviors than taxes; taxes are simpler than FAPs. Taxes are innate but dependent on the presence of a stimulus: when the stimulus ceases the taxis stops. But, FAPs continue after cessation of a stimulus (Tinbergen 1951). For example, extension of the fixed bug's proboscis coincident with the leg touching a drop of water may be catalogued as a reflex. Approach to the drop of water may be catalogued as a taxis. Proboscis extension and sucking are clearly part of the FAP, and at some point there is a superposition of all of them (Fig. 5).

FAPs are relatively unaffected by other environmental factors than the relevant stimulus, and once elicited cannot easily be interrupted (Craig 1918; Eibl-Eibesfeldt 1979). In our experiments, a $R$. prolixus bug, whose proboscis was inadvertently stuck to the head thus preventing its movement, performed desperate rapid epileptic movements associated with frustration (sensu Bekoff and Jamieson 1990), in a struggle to release its proboscis in order to accomplish its goal: to pierce and suck. Usually, this cascade of actions has such momentum that the insect may risk suffering damage. In Rhinocoris carmelita (Heteroptera: Reduviidae), proboscis extension and drinking was elicited by some solutions that caused damage to its gut and Malpighian tubules (Edwards 1962).

What role could proboscis-extension behavior play in the evolution of Triatominae? It seems likely that this FAP facilitated the change from predation to hematophagy (Otálora-Luna et al. 2015b). Presumably, early triatomines fed on abundant soft invertebrates in the nests and burrows of vertebrates, then later encountered their defenseless newly born offspring, tasted them, extended the proboscis, punctured and penetrated their skin. The elicitation flexibility of stimuli for triggering the proboscis-extension pattern was decisive in the change of behavior that permitted the "first" triatomines to become bloodsuckers.

Wigglesworth and Gillett (1934a, b) were unable to elicit proboscis extension in $R$. prolixus using mouse skin. According to Vinauger et al. (2013) "heat constitutes the only necessary and sufficient signal to trigger" what they called the proboscis-extension response (Flores and Lazzari 1996; Labrousse et al. 2017). These studies recognized proboscis extension as an innate behavior, which they labeled a

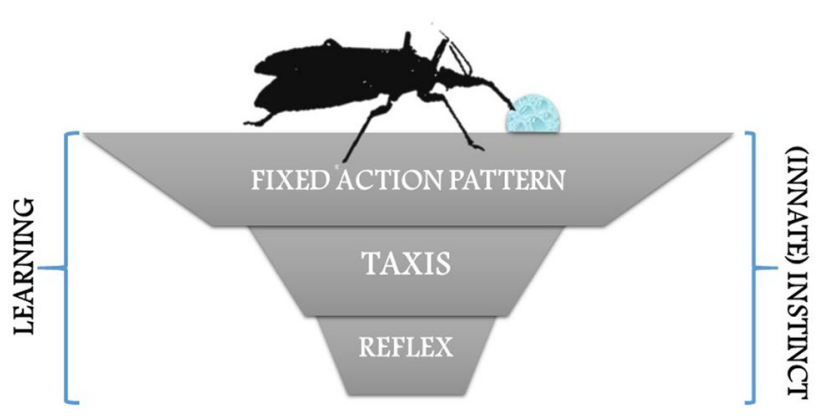

Fig. 5 The FAP associated with the proboscis extension might include taxis and reflex patterns, and although there is a clear hierarchy, it is not a simple sum of these. Each phenotypic pattern (FAP, taxis and reflex) has both a learning and an innate basis 
reflex. However, they did not consider PER as part of a more complex invariant behavior or FAP, and failed to recognize that other stimuli could elicit such PER. Hatfield et al. (1983) labeled a behavior associated with feeding in L. lineaolaris a FAP. The limited description of the FAP that these authors offered, makes it difficult to perform a comparison with the FAP documented here. We have observed that proboscis extension can be elicited by carbon dioxide and ammonia odors when presented to $R$. prolixus and $T$. infestans walking on a servosphere (unpublished data). Observations performed in this work suggested that gustation of clean water and (probable) vision of a dummy can elicit proboscis lifting, thus, adding to heat, chemical and visual signals as stimuli sufficient to elicit this FAP. Extirpation of the antennae showed that these organs are not required to elicit proboscis extension. Proboscis extension elicited by leg touching with a drop of water, demonstrated that this can be triggered by stimulating gustatory hairs present on the leg. FAPs are inflexible, but the stimuli that trigger them can be broad (Tinbergen 1951). Olfactory, gustatory and thermal stimuli nearly always trigger an invariable proboscis response. This behavioral flexibility allows triatomines to adapt to cleptohematophagy, cannibalism, coprophagy and phytophagy, as well as to the water-drinking behavior we observed here. Although triatomines had been categorized as being specialized in blood feeding (Otálora-Luna et al. 2015b), the recent discovery of the highly adaptative value of entomophagy in Belminus bugs, and the observation of other facultative sucking behaviors mentioned above, open a debate about the taxonomic value of hematophagy for Triatominae, where proboscis extension and sucking behaviors have to be studied in broader terms.

So why did these authors erroneously insist that temperature was the sole stimulus that could elicit the proboscis response? They were probably guided by the misconception that this behavior was linearly driven by natural selection (a type of orthoselection) of hematophagy, where heat emanating from a homeothermic vertebrate would be the best choice. Orthogenesis is an hypothesis that life has a tendency to evolve in a direction due to some "driving force;" although this subject is highly controversial and not accepted by most neo-Darwinists (Colacino and Grehan 2003; Heads 2017), there is no doubt that natural selection determines a direction (Gould 1982). However, such direction cannot be only guided by natural selection or linearly driven (OtáloraLuna et al. 2017). The multiple adaptations of the FAP associated with the proboscis extension suggest that this feature evolves and is not linearly driven by a particular function (e.g., hematophagy), but by a diversity of effects (cleptohematophagy, cannibalism, coprophagy and phytophagy, etc.).

It is tempting to define the proboscis-extension pattern as an adaptation in the neo-Darwinian sense. However, this FAP may have emerged during evolution as a product of a complex process where diverse behavioral reflexes, anatomical parts, physiological components and neural networks were joined in a versatile module (Gould 1992), i.e., interlocking parts that form a structural adaptation (Croizat 1962).

In this work, fifth-instar nymphs and adults only drank about $5 \mu$ of water. In contrast, they may ingest 140-180 mg of liquid when blood feeding (Wigglesworth 1931). What is the epidemiological relevance of triatomine gustation and sucking of such a small amount of water and fruit? Previous epidemiological reports have associated guava fruit, as well as other fruits like sugar cane, with oral transmission of Chagas disease (Áñez et al. 2013). We propose that if triatomines use certain fruits as a source of water, vitamins and sugars, this could increase the probability of finding an infected bug or its bodily excretions in juice for human consumption.

Concerning other modalities, historically volatile chemicals produced by hosts have received special attention by most triatomine researchers. It has been demonstrated that skin and breath odors such as carbon dioxide, ammonia, carboxylic acids, alcohols, aldehydes, aromatics (OtáloraLuna et al. 2004; Guerenstein and Lazzari 2009; Ortiz and Molina 2010) and amines (Otálora-Luna and Guerin 2014) play a role in attracting triatomines to their hosts. We propose that in some circumstances some or all of these odors may elicit proboscis extension. Although not observed in triatomines, we have observed some assessing bugs (Reduviidae) in the field responding by extending their proboscis when feeling threatened. Triatomine proboscis extension could also serve as a defense behavior, inherited from their reduviid ancestors, which have a very painful bite.

Some predatory reduviids have been observed using their sense of taste-with their antennae, legs and proboscis - and have been observed drinking water (Miller 1953; Edwards 1962). Edwards (1962) performed behavioral gustatory experiments using aqueous solutions to stimulate the tip of the antennae of $R$. carmelita, which elicited proboscis extension and suction. The presence of fossula spongiosa on triatomine legs probably has a role in leg gustation, as suggested by Edwards (1962) when working with other reduviids. As mentioned above, DíazAlbiter et al. (2016) found that $R$. prolixus take water and sugars from tomatoes.

To the best of our knowledge, ours is the first ethological report of Triatominae (1) performing a FAP, (2) imbibing from a drop of water, and (3) imbibing from guava fruit. Given that, in our study, vision of a dummy or tasting of a drop of water (and guava) preceded an attempt to suck, our results reveal a versatile FAP evoked by visual and gustatory cues. 


\section{References}

Aldana E, Otálora F, Abramson CI (2005) A new apparatus to study behavior of triatomines under laboratory conditions. Psychol Rep 96:825-832

Alves CL, Araujo RN, Gontijo NF, Pereira MH (2011) Importance and physiological effects of hemolymphagy in triatomines (Hemiptera: Reduviidae). J Med Entomol 48:372-381

Áñez N (1982) Studies on Trypanosoma rangeli Tejera, 1920. III. Direct transmission of Trypanosoma rangeli between triatomine bugs. Ann Trop Med Parasitol 76:641-647

Áñez N, Crisante G, Rojas A, Dávila D (2013) Brote de enfermedad de Chagas agudo de posible transmisión oral en Mérida, Venezuela. Bol Mal Salud Amb 53:1-11

Bailly F, Longo G, Montevil M (2012) A 2-dimensional geometry for biological time. Prog Biophys Mol Biol 106:474-484

Bekoff M (2007) Pasiones animales y virtudes bestiales: la etología cognitiva como la ciencia unificadora para la comprensión de las vidas subjetivas, emocionales, empáticas y morales de los animales. REDVET Rev Electron Vet 1695:7504

Bekoff M, Jamieson D (1990) Cognitive ethology and applied philosophy: the significance of an evolutionary biology of mind. Trends Ecol Evol 5:156-159

Castro M, Barrett TV, Santos WS, Abad-Franch F, Rafael JA (2010) Attraction of Chagas disease vectors (Triatominae) to artificial light sources in the canopy of primary Amazon rainforest. Mem Inst Oswaldo Cruz 105:1061-1064

Colacino C, Grehan JR (2003) Ostracismo alle frontiere della biologia evoluzionistica: il caso Léon Croizat. In: Mamone Capria M (ed) Scienza e Democrazia. Liguori, Napoli, pp 195-220. ISBN 88-207-3495-8

Craig W (1918) Appetites and aversions as constituents of instincts. Sci Am 85:291. https://doi.org/10.1038/scientificamerican05 111918-291asupp

Crist E (1998) The ethological constitution of animals as natural objects: the technical writings of Konrad Lorenz and Nikolaas Tinbergen. Biol Philos 13:61-102

Croizat L (1962) Space, time, form: the biological synthesis. Published by the author, Caracas

Darwin C (1983) El origen de las especies. del Serbal, Barcelona

Darwin C, Wallace A (1858) On the tendency of species to form varieties; and on the perpetuation of varieties and species by natural means of selection. J Proc Linn Soc Lond Zool 3:45-62

Díaz-Albiter HM, Ferreira TN, Costa SG, Rivas GB, Gumiel M, Cavalcante DR, Pavan MG, Gonzalez MS, de Mello CB, Dillon VM, Bruno RV, Genta FA (2016) Everybody loves sugar: first report of plant feeding in triatomines. Parasites Vectors 9:114

Durán P, Siñani E, Depickère S (2016) On triatomines, cockroaches and haemolymphagy under laboratory conditions: new discoveries. Mem Inst Oswaldo Cruz 111:605-613

Edwards J (1962) A note on water uptake and gustatory discrimination in a predatory reduviid (Hemiptera). J Insect Physiol 8:113-115

Eibl-Eibesfeldt I (1979) Etología: introducción al estudio comparado del comportamiento, 2nd edn. Omega, Spain

Ferreira RA, Lazzari CR, Lorenzo MG, Pereira MH (2007) Do haematophagous bugs assess skin surface temperature to detect blood vessels? PLoS ONE 2(9):e932

Flores GB, Lazzari CR (1996) The role of the antennae in Triatoma infestans: orientation towards thermal sources. J Insect Physiol 42:433-440

Fresquet N, Lazzari CR (2011) Response to heat in Rhodnius prolixus: the role of the thermal background. J Insect Physiol 57:1446-1449

Friend WG, Smith JJB (1977) Factors affecting feeding by bloodsucking insects. Annu Rev Entomol 22:309-331
García Bacca JD (1985) Necesidad y azar: Parménides (s. V a.C.) - Mallarmé (s. XIX d.C.). Antrophos - Editorial del Hombre, Barcelona

Gould SJ (1982) Darwinism and the expansion of the evolutionary theory. Science 216:380-387

Gould SJ (1992) Roots: ontogeny and phylogeny-revisited and reunited. BioEssays 14:275-279

Gould SJ, Vrba ES (1982) Exaptation-a missing term in the science of form. Paleobiology 8:4-15

Grehan J (1984) Evolution by law: Croizat's “orthogeny” and Darwin's laws of growth. Tuatara 27:14-19

Guerenstein PG, Lazzari CR (2009) Host-seeking: how triatomines acquire and make use of information to find blood. Acta Trop 110:148-158

Guerenstein PG, Núñez JA (1994) Feeding response of the haematophagous bugs Rhodnius prolixus and Triatoma infestans to saline solutions: a comparative study. J Insect Physiol 40:747-752

Hatfield LD, Ferreira J, Frazier JL (1983) Host selection and feeding behavior by the tarnished plant bug, Lygus lineolaris (Hemiptera: Miridae). Ann Entomol Soc Am 76:688-691

Heads M (2017) Biography and evolution in New Zealand. CRC, Boca Ratón

Humboldt A (1991) Viaje a las regiones equinocciales del nuevo continente (1799-1800). Monte Avila, Caracas

Immelmann K (1983) Introduction to ethology, 2nd edn. Plenum, New York

Kogon C (1941) Das Instinktive als philosophisches problem. Trilsch, Dresden

Kusumaatmaja H, Vrancken RJ, Bastiaansen CWM, Yeomans JM (2008) Anisotropic drop morphologies on corrugated surfaces. arXiv preprint arXiv:0805.0063

Labrousse C, Lazzari C, Fresquet N (2017) Developmental study of the proboscis extension response to heat in Rhodnius prolixus along the life cycle. J Insect Physiol 98:55-58

Lorenz K (1977) El comportamiento animal y humano, 1st edn. Plaza \& Janes, Barcelona

Lorenz K (1981) The foundations of ethology. Springer, Heidelberg Berlin New York

Mendl M, Paul ES, Chittka L (2011) Animal behaviour: emotion in invertebrates? Curr Biol 21:R463-R465

Miller NCE (1953) Notes on the biology of the Reduviidae of Southern Rhodesia. Trans Zool Soc Lond 27:541-672

Ortiz MI, Molina J (2010) Preliminary evidence of Rhodnius prolixus (Hemiptera: Triatominae) attraction to human skin odour extracts. Acta Trop 113:174-179

Otálora-Luna F, Guerin P (2014) Amines from vertebrates guide triatomine bugs to resources. J Insect Physiol 71:52-60

Otálora-Luna F, Perret JL, Guerin PM (2004) Appetence behaviours of the triatomine bug Rhodnius prolixus on a servosphere in response to the host metabolites carbon dioxide and ammonia. J Comp Physiol A 190:847-854

Otálora-Luna F, Aldana E, Viloria A (2015a) Triatomines or humans: who are the invaders? Ludus Vitalis 43:223-230

Otálora-Luna F, Pérez-Sánchez AJ, Sandoval C, Aldana E (2015b) Evolution of hematophagous habit in Triatominae (Heteroptera: Reduviidae). Rev Chil Hist Nat. https://doi.org/10.1186/s4069 3-014-0032-0

Otálora-Luna F, Aldana E, Viloria A (2017) Crítica a la teoría de la evolución pura: hacia la belleza estructural. Ludus Vitalis 25(47):167-185

Pacheco-Tucuch FS, Ramirez-Sierra MJ, Gourbière S, Dumonteil E (2012) Public street lights increase house infestation by the Chagas disease vector Triatoma dimidiata. PLoS ONE. https://doi. org/10.1371/journal.pone.0036207

Paul E, Mendl M (2016) If insects have phenomenal consciousness, could they suffer? Anim Sentience 1:16 
Pontes G, Minoli S, Insaurralde IO, Brito Sanchez MG, Barrozo RB (2014) Bitter stimuli modulate the feeding decision of a bloodsucking insect via two sensory inputs. J Exp Biol 217:3708-3717

Raad H, Ferveur JF, Ledger N, Capovilla M, Robichon A (2016) Functional gustatory role of chemoreceptors in Drosophila wings. Cell Rep 15:1442-1454

Reisenman CE, Lazzari C (2006) Spectral sensitivity of the photonegative reaction of the blood-sucking bug Triatoma infestans (Heteroptera: Reduviidae). J Comp Physiol A 192:39-44

Roeder K (1998) Nerve cells and insect behavior, 2nd edn. Harvard University Press, Cambridge

Sandoval CM, Medone P, Nieves EE, Jaimes DA, Ortiz N, Rabinovich JE (2013) Demographic fitness of Belminus ferroae (Hemiptera: Triatominae) on three different hosts under laboratory conditions. Mem Inst Oswaldo Cruz 108:854-864

Sandoval CM, Nieves EE, Gutiérrez R, Jaimes DA, Ortiz N, OtáloraLuna F, Aldana EJ (2015) Morphometric analysis of the host effect on phenotypical variation of Belminus ferroae (Hemiptera: Triatominae). Psyche. https://doi.org/10.1155/2015/613614

Schaub GA, Böker CA, Jensen C, Reduth D (1989) Cannibalism and coprophagy are modes of transmission of Blastocrithidia triatomae (Trypanosomatidae) between triatomines. J Eukaryot Microbiol 36:171-175

Schmitz H, Trenner S, Hofmann MH, Bleckmann H (2000) The ability of Rhodnius prolixus (Hemiptera; Reduviidae) to approach a thermal source solely by its infrared radiation. J Insect Physiol $46: 745-751$
Semprebon C, Mistura G, Orlandini E, Bissacco G, Segato A, Yeomans JM (2009) Anisotropy of water droplets on single rectangular posts. Langmuir 25:5619-5625

Singh R (1997) Neurobiology of the gustatory systems of Drosophila and some terrestrial insects. Microsc Res Tech 39:547-563

Tiffin H (2016) Do insects feel pain? Anim Studies J 5:80-96

Tinbergen N (1951) The study of instinct. Oxford University Press, New York

Tinbergen N (1986) Naturalistas curiosos, 1st edn. Salvat, Barcelona

Tinbergen N (2006) El estudio del instinto, 1st edn. Siglo XXI, Cerro del Agua

Vinauger C, Lallement H, Lazzari CR (2013) Learning and memory in Rhodnius prolixus: habituation and aversive operant conditioning of the proboscis extension response. J Exp Biol 216:892-900

Ward JP, Finlayson LH (1982) Behavioural responses of the haematophagous bug Triatoma infestans (Klug) (Hemiptera: Reduviidae) to visual stimuli. Bull Entomol Res 72:357-366

Wigglesworth V (1931) The physiology of excretion in a blood-sucking insect, Rhodnius prolixus (Hemiptera, Reduviidae). J Exp Biol 8:411-427

Wigglesworth V, Gillett J (1934a) The function of antennae in Rhodnius prolixus (Hemiptera) and the mechanism of orientation to the host. J Exp Biol 11:120-139

Wigglesworth V, Gillett J (1934b) The function of the antennae in Rhodnius prolixus: confirmatory experiments. J Exp Biol 11:408 